\title{
Effects of dual identification and interteam conflict on multiteam system performance
}

Citation for published version (APA):

Cuijpers, M. P. J., Uitdewilligen, G. J. A. M. L., \& Günter, H. (2016). Effects of dual identification and interteam conflict on multiteam system performance. Journal of Occupational and Organizational Psychology, 89(1), 141-171. https://doi.org/10.1111/joop.12113

Document status and date:

Published: 01/03/2016

DOI:

10.1111/joop.12113

Document Version:

Publisher's PDF, also known as Version of record

Document license:

Taverne

Please check the document version of this publication:

- A submitted manuscript is the version of the article upon submission and before peer-review. There can be important differences between the submitted version and the official published version of record.

People interested in the research are advised to contact the author for the final version of the publication, or visit the DOI to the publisher's website.

- The final author version and the galley proof are versions of the publication after peer review.

- The final published version features the final layout of the paper including the volume, issue and page numbers.

Link to publication

\footnotetext{
General rights rights.

- You may freely distribute the URL identifying the publication in the public portal. please follow below link for the End User Agreement:

www.umlib.nl/taverne-license

Take down policy

If you believe that this document breaches copyright please contact us at:

repository@maastrichtuniversity.nl

providing details and we will investigate your claim.
}

Copyright and moral rights for the publications made accessible in the public portal are retained by the authors and/or other copyright owners and it is a condition of accessing publications that users recognise and abide by the legal requirements associated with these

- Users may download and print one copy of any publication from the public portal for the purpose of private study or research.

- You may not further distribute the material or use it for any profit-making activity or commercial gain

If the publication is distributed under the terms of Article $25 \mathrm{fa}$ of the Dutch Copyright Act, indicated by the "Taverne" license above, 


\title{
Effects of dual identification and interteam conflict on multiteam system performance
}

\author{
Maarten Cuijpers ${ }^{1}$, Sjir Uitdewilligen ${ }^{2}$ and Hannes Guenter ${ }^{3}$ \\ 'School of Governance, Law \& Urban Development, Saxion University of Applied \\ Sciences, Enschede, The Netherlands \\ ${ }^{2}$ Faculty of Psychology and Neuroscience, Maastricht University, The Netherlands \\ ${ }^{3}$ Department of Organization \& Strategy, Maastricht University School of Business and \\ Economics, The Netherlands
}

\begin{abstract}
In this study, we investigate how multiteam system (MTS) and component team identification influence interteam conflict and MTS performance. On the basis of resource allocation theory and social identity theory, we build a model to examine dual identification and its effects in MTSs. We use a real-time computer simulation to test our hypotheses and measure our focal constructs in three consecutive performance episodes. Using random coefficient modelling, we find that MTS identification is associated positively with MTS performance, and interteam task and relationship conflict mediate this relationship. Team identification influenced interteam conflict at the start of the study, but this influence decreased over time. Although the effect of MTS identification appears to be more prominent than the effect of team identification, our results point at the importance of investigating the identification with the MTS relative to that of the team. We discuss implications for MTS theory and practice.
\end{abstract}

\section{Practitioner points}

- Although organizations increasingly rely on multiteam systems to accomplish work, the drivers of multiteam system performance remain understudied.

- This study establishes multiteam system identification as the principal determinant of interteam conflict and multiteam system performance.

- For multiteam system members, it is critical to engage in practices that make them quickly identify with the multiteam system.

A new stream of research is gaining momentum, which aims at going beyond looking at the team as an isolated entity. This research focuses on the interactions that take place among multiple teams and investigates how collectives of teams perform (DeChurch \& Marks, 2006). These collectives of teams - also referred to as multiteam systems (MTSs) have common goals, but they also need to align the goals of the individual teams (Marks, DeChurch, Mathieu, Panzer, \& Alonso, 2005; Mathieu, Marks, \& Zaccaro, 2001). For example, emergency management systems consist of police teams, fire brigade teams, and medical teams that need to cooperate in the case of emergencies (Mathieu et al., 2001).

*Correspondence should be addressed to Maarten Cuijpers, School of Governance, Law \& Urban Development, Saxion University of Applied Sciences, M.H. Tromplaan 28, PO Box 70.000, 7500 KB Enschede, The Netherlands (email: m.p.j. cuijpers@saxion.nl). 
Although these teams share the overarching goal of containing an incident and saving people's lives, they also pursue their own goals (e.g., treating injured people or rescuing people from fire; Mathieu et al., 2001). Previous research suggests that differences in goals can cause intergroup tensions if they are not tackled upfront (DeChurch \& Zaccaro, 2010; Kanfer \& Ackerman, 1989). Differences in team interests may demarcate perceived boundaries between teams and cause negative perceptions of other teams (Hornsey \& Hogg, 2000; Tajfel, 1982). To ensure that an MTS functions as a collective, it is therefore crucial that interteam tensions are kept at bay.

Research on (inter) group collaboration has identified various means that help prevent and attenuate such interteam tensions, such as interteam coordination (Hoegl, Weinkauf, \& Gemuenden, 2004; Marks et al., 2005), interface project management (Hoegl \& Weinkauf, 2005), and (intergroup) leadership (DeChurch \& Marks, 2006; Hogg, van Knippenberg, \& Rast, 2012; Murase, Carter, DeChurch, \& Marks, 2014). Hogg et al. (2012), for example, suggested that intergroup leadership helps reduce intergroup biases to the extent that leaders recognize and reaffirm groups' distinct and valued identities. Although these findings are encouraging and important, research into the effects of MTS and team goal preferences on interteam functioning and performance is largely absent. The existence of both interteam (i.e., MTS) and intrateam (i.e., component team) goals creates a complex structure that produces a constant trade-off between the accomplishment of MTS- and team-level responsibilities.

In this study, we build and test a conceptual model that assesses how both MTS- and team-level identification interactively shape MTS performance. We draw from social identity theory (Tajfel, 1982) and resource allocation theory (Kanfer \& Ackerman, 1989; Kramer \& Brewer, 1984) to derive hypotheses on how discrepancies in MTS- and teamlevel responsibilities influence interteam conflict and MTS performance. Specifically, we take a dual identification perspective (Hogg \& Terry, 2000) to study how MTS and team identification influence interteam conflict interactively and, in turn, MTS performance. Figure 1 summarizes these relationships. We tested our theoretical model in the context of emergency response MTSs composed of a set of response units (e.g., firefighting teams;

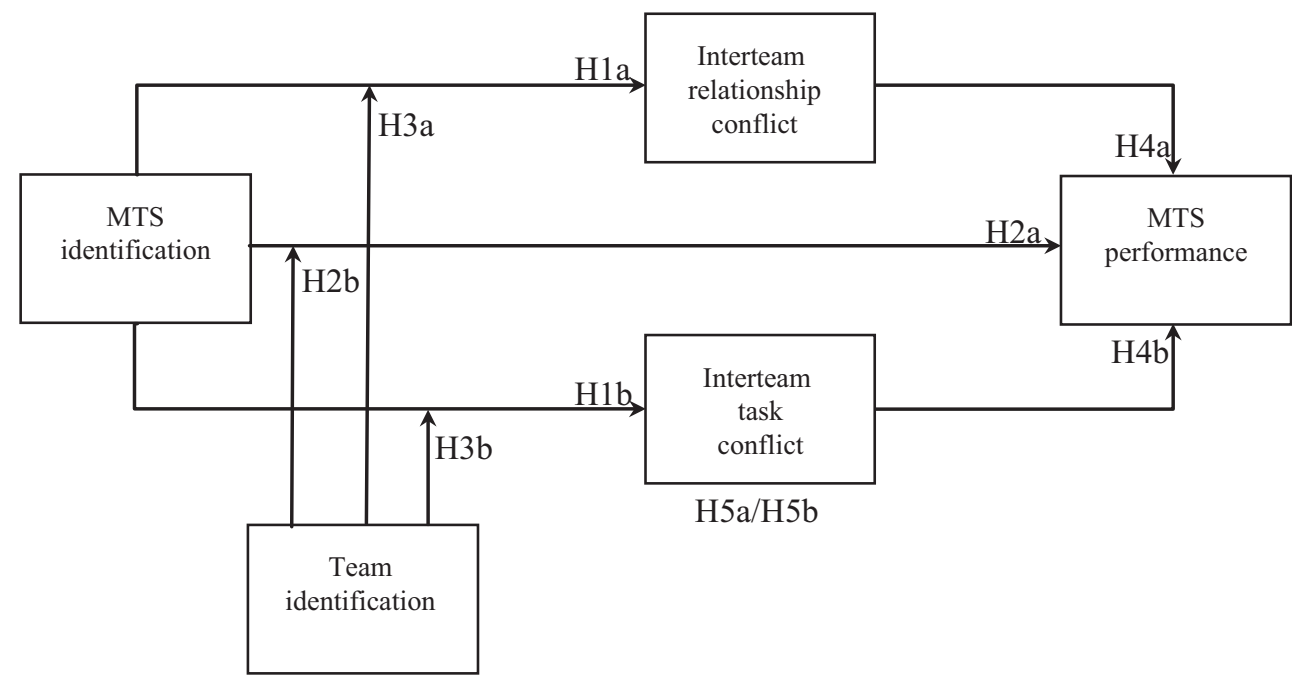

Figure I. Conceptual model: Multiteam system (MTS) and team identification, conflict, and MTS performance. 
DeChurch \& Marks, 2006). MTSs are formed to perform in turbulent, time-pressured contexts in which multiple teams need to coordinate their activities and respond rapidly (Mathieu et al., 2001). Interteam conflicts may arise because an emergency response requires interdependent teams to coordinate their efforts under time pressure and in a situation of high uncertainty. Furthermore, given that members of emergency component teams may identify more strongly with their team than the MTS, resources may be misallocated when responding to emergencies, potentially interfering with MTS performance. Taken together, in our study, we focus on a context relevant to where identity-based interteam conflicts can have disastrous consequences both to property and to life.

Our study makes three specific contributions to the literature. Firstly, we add to the MTS literature in assessing how identification impacts interteam conflict and performance. MTS studies have assessed the differential effects of interteam and intrateam processes (DeChurch \& Marks, 2006; Marks et al., 2005), but we are not aware of studies investigating how team factors (e.g., team identification) and MTS factors (e.g., MTS identification) influence interteam outcomes interactively (e.g., MTS performance; for an exception, see Firth, Hollenbeck, Miles, Ilgen, \& Barnes, 2015). Secondly, we contribute more generally to the literature on (inter) group collaboration by providing new insights into how (inter) group collaboration may be improved (Hoegl et al., 2004; Hogg et al., 2012). Thirdly, we measure our focal constructs repeatedly over time (i.e., across three moments) to assess the trajectories of these constructs, as well as the stability of the hypothesized relationships among the constructs over time. In doing so, we extend the reach of social identity literature which is primarily cross-sectional in nature (Gonzalez \& Brown, 2003; Hornsey \& Hogg, 2000), and respond to calls in the MTS literature to study performance effects over time (Davison, Hollenbeck, Barnes, Sleesman, \& Ilgen, 2012).

\section{Theory and hypotheses}

\section{Defining characteristics of MTSs}

MTSs are constellations of two or more interdependent component teams that depend on each other in terms of inputs, processes, and outcomes (Mathieu et al., 2001). Component teams work towards a shared MTS goal, but also pursue individual team goals. The accomplishment of the overall goal of the MTS is dependent upon, but still different from, the accomplishment of the individual team goals (Firth et al., 2015; Marks et al., 2005; Mathieu et al., 2001). For example, the goal accomplishment of an emergency management system depends on how well police teams, fire brigade teams, and medical teams comply with their responsibilities of cordoning off premises, extinguishing fires, and rescuing victims. These component team goals, however, 'must be aggregated to a higher level in a goal hierarchy for an MTS to exist' (Marks et al., 2005, p. 965). How well each individual component team performs its individual goal eventually determines the success of the MTS.

However, component team goals are not always aligned and members may favour them to the detriment of the aggregated MTS goals (Davison et al., 2012). This may hamper interteam coordination and undermine the exchange of resources across team boundaries (Mathieu et al., 2001). For example, when a police team cordons off premises for security reasons, this may prevent the medical team from reaching the victims quickly. Although it is in the best interest of the police team to cordon off the environment, favouring this individual team goal may somewhat hamper the medical team's actions and 
thereby, in turn, complicate the achievement of the overarching MTS goal (i.e., to effectively and efficiently manage the emergency). Finding a balance between team goals and the overarching MTS goals is therefore critical for MTS performance. In the following sections, we describe how resource allocation theory (Kanfer \& Ackerman, 1989) and social identity theory (Hogg \& Terry, 2000) help predict MTS conflict and performance, given varying degrees of interteam goal alignment.

\section{Cross-level goal preferences and MTS performance}

Resource allocation theory (Kanfer \& Ackerman, 1989) suggests individual task performance depends on the cognitive resources devoted to the task; individuals have limited cognitive resources, so attention devoted to one task cannot be assigned to another task. The same principle applies to teams (Barnes et al., 2008): If team members assign resources to one team goal, they may not have sufficient resources left for the accomplishment of competing team goals. This implies that when MTS members devote resources to team goal accomplishment, fewer resources can be allocated to MTS goals, and vice versa. Although, typically, overlap exists between team and MTS goals, MTS performance may still suffer when MTS members focus on team goals and ignore MTS goals (DeChurch \& Zaccaro, 2010). Thus, the effective distribution of resources among interdependent teams is critical to MTS performance (Marks et al., 2005; Porter, Gogus, \& Yu, 2010).

According to social identity theory, resource allocation depends upon how strongly individuals feel attached to a collective (e.g., team). Feeling attached to a collective helps people to (1) satisfy their need for self-enhancement, (2) reduce uncertainty, and (3) feel distinct. People who identify with a collective also favour its members, goals, and interests over those of other collectives (Tajfel, 1982). Recently, social identification researchers have recognized that people are able to identify with multiple collectives (Hornsey \& Hogg, 2000; van Dick, van Knippenberg, Kerschreiter, Hertel, \& Wieseke, 2008). Within the context of an MTS, this implies that MTS members may identify with both the overarching MTS and their team, and resource allocation in an MTS should indeed be optimal when members identify with both entities (Brewer, 1991; Hogg \& Terry, 2000; Richter, West, van Dick, \& Dawson, 2006). We therefore propose that MTS performance depends upon how strongly MTS members identify with both the MTS and the team.

\section{Effect of MTS and team identification on MTS performance}

For an MTS to function well, it is critical that members allocate resources to MTS goals and not only to team goals. Marks et al. (2005) found that when resource allocation is coordinated at the MTS level, MTS performance benefits. Similarly, DeChurch and Marks (2006) showed that leadership interventions at the MTS level are most effective for MTS performance, whereas leadership interventions at the team level mainly improve team performance.

But what factors influence a balanced distribution of resources to the team and the MTS? As stated in social identification theory, resources are allocated to a higher level entity according to the extent to which members identify with this entity (Dutton, Dukerich, \& Harquail, 1994; Kramer \& Brewer, 1984). Ullrich, Wieseke, Christ, Schulze, and Van Dick (2007) found support for this view when studying the effects of organizational and corporate identification among franchise employees. Although identification with the corporation positively influenced corporate citizenship behaviour, 
organizational identification influenced customer-oriented behaviour. Therefore, we assume:

\section{Hypothesis la: MTS identification is positively related to MTS performance.}

When members identify with only one of the two entities (team or MTS), they internalize the respective goals and interests of this one particular entity alone (Tajfel, 1982), and allocate resources accordingly (Kanfer \& Ackerman, 1989). If team members, however, identify simultaneously with both the MTS and the team, they may better understand and integrate their twofold responsibilities and allocate their resources across these entities in a more balanced way (Glynn, Kazanjian, \& Drazin, 2010; Pratt, Rockmann, \& Kaufmann, 2006; Vora \& Kostova, 2007). Dual identification - high identification with both the MTS and the team - is thus essential for both MTS- and team-level goals to be accomplished (Brewer, 1991). Hoegl et al.'s (2004) research on multiteam R\&D projects in the automotive industry suggests that attachment to both the individual project team and the overall project is needed to achieve optimal performance. Similarly, we argue that both MTS identification and team identification are needed for the optimal allocation of resources to the MTS and the team.

Hypothesis Ib: MTS identification is more strongly and positively related to MTS performance when team identification is high than when it is low.

\section{Effects of MTS and team identification on interteam conflict}

Component teams of an MTS often differ in terms of functional background, expertise, and experience, thus bringing different perspectives to the task at hand. To the extent that team members consider their team's perspective to be more valid than the perspective of the other team (Hogg \& Terry, 2000), disagreements and task conflicts may arise (Jehn, 1995; Jehn \& Mannix, 2001). Task conflicts may increase further when members of one team lack an understanding of the goal and task execution preferences of the other team (Jehn, Chadwick, \& Thatcher, 1997). Additionally, because MTS members belong to different teams, ingroup/outgroup bias may be the result. Members of the ingroup are perceived as commendable and trustworthy, whereas outgroup members are seen as lamentable and unreliable. Such bias may hamper the exchange of information and knowledge across teams and may create a competitive and hostile atmosphere that endangers the social harmony in the MTS (Hornsey \& Hogg, 2000; Tajfel, 1982). Tension, disharmony, and animosity describe what is commonly referred to as relationship conflict (Jehn, 1995).

MTS identification may decrease interteam task and relationship conflict (Gaertner, Dovidio, Anastasio, Bachman, \& Rust, 1993; Hornsey \& Hogg, 2000) and may encourage teams to accomplish the overarching goals of the MTS jointly (Marks et al., 2005). Intergroup relations theorists suggest that an overarching identity will decrease task and relationship conflict because a common identity helps to align various - potentially conflicting - team goals and ideas (Brewer, 1991; Mortensen \& Hinds, 2001). Mortensen and Hinds (2001), for example, found that collective identification reduced both task and relationship conflict by creating a 'we are in this together' style of thinking. When people identify with the overarching MTS, attention to the differences between teams is replaced by an emphasis on what MTS members have in common. Identification with the MTS therefore positively affects the alignment of thoughts, feelings, and actions, which is an 
important precondition for the integration of divergent ideas and perspectives (van der Vegt \& Bunderson, 2005). Accordingly, Moore, Kurtzberg, Thompson, and Morris (1999) found that the absence of collective identification complicated rapport building and negatively impacted intergroup relations both on and off the task.

Hypothesis 2a: MTS identification is negatively related to interteam relationship conflict.

Hypothesis $2 b$ : MTS identification is negatively related to interteam task conflict.

Although MTS identification benefits interteam functioning, the effects of MTS identification on task and relationship conflict also depend on the degree to which members identify with their team. The principle of optimal distinctiveness (Brewer, 1991) supports this view and suggests that any individual simultaneously strives to belong to a larger group (i.e., need for inclusiveness) and to maintain a distinct identity (i.e., need for differentiation). Although MTS identification satisfies MTS members' need for inclusiveness, MTS identification may thwart MTS members' need for differentiation (Brewer, 1991; Hogg \& Terry, 2000). To counter this sense of being 'overincluded', MTS members engage in ingroup favouring behaviour to differentiate themselves from other teams, and this distorts interteam relations (Brewer, 1991). Identifying with a lower order entity (i.e., team) in addition to a higher order entity (i.e., MTS) is therefore critical, as this allows MTS members to feel simultaneously unique and different from other teams in the MTS (Brewer, 1991).

By simultaneously identifying with the MTS and the team, the chances of both task and relationship conflicts arising are reduced. As far as task conflict is concerned, we propose that this is because members need to account for different viewpoints (i.e., team-based and MTS-based viewpoints), which makes it less likely that they ignore or understate the importance of the other team's perspective. Similarly, the greater the access that team members have to different perspectives and viewpoints (i.e., team and MTS perspective), the easier it should be for members to align expectations and develop a shared understanding, both within and across teams (Hinsz \& Betts, 2012). Thus, to the extent that teams begin to build shared understanding, task conflict between teams should be less likely (Cronin \& Weingart, 2007). Concerning relationship conflict, we argue that team identification, in conjunction with MTS identification, helps avoid interteam bias and relationship conflict. If members only identify with the MTS but not with the team, their need for differentiation is thwarted, possibly giving rise to interteam tensions and animosities (Chen, Kanfer, DeShon, Mathieu, \& Kozlowski, 2009). The same is true for occasions when members do not feel included in the MTS, such as when they only identify with the team but not with the MTS; in this case, ingroup/outgroup biases are likely to emerge, making interteam relationship conflicts more likely. However, if members identify with both entities simultaneously (i.e., team and MTS), interteam relationship conflicts are less likely (Brewer, 1991).

Recent research confirms the beneficial relation between dual identification and interteam relations and productivity (Richter et al., 2006; Vora, Kostova, \& Roth, 2007). Richter et al. (2006), for example, tested dual identification processes among health care employees. They found that employees' organizational identification was more strongly related to effective interteam relations when their work team identification was high rather than low. Dual identification seems to suppress the experience of being torn between MTS and component team responsibilities (DeChurch \& Zaccaro, 2010). 
Hypothesis 3a: The relationship between MTS identification and interteam relationship conflict is more negative when team identification is high than when it is low.

Hypothesis 3b: The relationship between MTS identification and interteam task conflict is more negative when team identification is high than when it is low.

\section{Effect of interteam relationship and task conflict on MTS performance}

Research on the consequences of relationship conflict within teams consistently supports the view that relationship conflict is detrimental to collective performance (De Wit, Greer, \& Jehn, 2012). There are several reasons for the negative implications of relationship conflict. Firstly, time and effort that could be devoted to executing the task at hand go into resolving animosities (Jehn, 1995). Secondly, relationship conflict increases arousal, which, in turn, reduces the members' cognitive flexibility and information processing capacity (De Dreu \& Weingart, 2003). Thirdly, relationship conflict generates stress and anxiety, which reduces decision-making quality and problem-solving capabilities (Peterson \& Behfar, 2003; Simons \& Peterson, 2000).

The fact that relationship conflict negatively influences team performance is something that we know mainly from within-team research. Still, we also expect such negative effects to hold (or to be even stronger) for between-team relationship conflicts (Hinsz \& Betts, 2012). This is because relationship conflict can create competitive mindsets between teams, which, in turn, hinders cooperation and undermines performance. This view is consistent with Tjosvold's (1998) theory of cooperation and competition, according to which people with a competitive mindset believe their goals to be negatively related, so that one's successful goal attainment makes others less likely to reach their goals. When members of one team perceive their goals to be negatively related to those of the other team, this is likely to reduce cooperative behaviours between teams and may limit effort allocation to collective MTS goals (DeChurch \& Zaccaro, 2010; Hinsz \& Betts, 2012). Because the teams in an MTS are dependent on each other for resources, interteam relationship conflict can reduce access to valued resources. In addition, interteam relationship conflict can limit the willingness of team members to help members of the other team and it can also reduce communication between teams, which can lead to costly errors and inferior decision-making (Hogg \& Terry, 2000; Meth, Lawless, \& Hawryluck, 2009).

Hypothesis 4a: Interteam relationship conflict is negatively related to MTS performance.

Research findings on the consequences of task conflict within teams are less straightforward than findings on relationship conflict (De Wit et al., 2012). De Dreu and Weingart (2003) found a strong and negative correlation between task conflict and team performance. De Wit et al. (2012), however, in a more extensive meta-analysis ( $n=7,200$ teams), did not find an overall negative effect; still, they found task conflict to negatively associate with team performance in non-top management teams, such as emergency response teams. De Wit et al. (2012) also found task conflict to be related negatively to performance when task conflicts co-occurred with other kinds of conflicts (e.g., relationship conflicts). Overall, intrateam research has produced mixed findings on the performance implications of task conflict. 
Here, we focus on interteam task conflict, which we expect to have overall negative performance implications, and this is mainly for three reasons. Firstly, when disagreement over task issues is distributed over clearly demarcated boundaries (e.g., over teams in MTSs), a constructive integration of the various perspectives is less likely to occur than when disagreement is more evenly distributed among the members (Li \& Hambrick, 2005). Task conflict between teams can lead members to limit their communication and interactions with members of the other team relative to their communication with members of their own team, thereby reinforcing disagreements (Jackson, 2002; Meth et al., 2009). Secondly, task conflict is especially likely to co-occur with relationship conflict when trust in the team is low and team communication impaired (Simons \& Peterson, 2000). MTSs that rely heavily on information and communication technologies (such as those often found in the emergency services) may be especially prone to suffer from task conflicts. Thirdly, MTSs often operate under extreme uncertainty and time pressure, which further increases the risk that task conflict interferes with the accomplishment of team goals (Carnevale \& Probst, 1998). Consistent with this argumentation, and in alignment with De Dreu's (2008) conclusion that 'positive functions of conflict are only found under an exceedingly limited set of circumstances' (p. 14), we would expect interteam task conflicts to have a negative association with MTS performance overall.

Hypothesis 4b: Interteam task conflict is negatively related to MTS performance.

By extension we hypothesize that:

Hypothesis 5a: Interteam relationship conflict mediates the association between MTS identification and MTS performance.

Hypothesis 5b: Interteam task conflict mediates the association between MTS identification and MTS performance.

\section{MTSs over time}

Although MTSs are typically defined by their relatively static structural components, in reality they are dynamic entities that develop and change over time (DeChurch \& Zaccaro, 2010; Standifer, 2012). From the inception of an MTS, its members are likely to accumulate experiences with and expectations of the interactions between the component teams (Caldwell, 2005). This accumulated experience, captured by the passage of time, may impact the average levels of identity, conflict, and performance in an MTS. For instance, interteam learning may cause the average performance of an MTS to increase over consecutive performance episodes. In addition, time may impact the relationships among the focal constructs (George \& Jones, 2000). Social identity scholars, in particular, have discussed how contextual factors may impact the salience, and hence the effects, of specific identities in a given situation (Hogg, Terry, \& White, 1995). Time can function as one such contextual factor that strengthens or weakens the effects of identity and conflict in MTSs. To account for this possible influence of time, we measured our focal constructs over three time points. Although the existing MTS literature does not provide sufficient ground to formulate directed temporal hypotheses, using a longitudinal design, we were able to assess how our focal constructs changed over time and whether the relationships among them remained stable. 


\section{Method}

\section{Study design}

To test our hypotheses, we conducted a simulation study that took place in the laboratory. We used a 3-hr real-time command-and-control firefighting computer simulation, called Networked Fire Chief (NFC; Omodei, Taranto, \& Wearing, 2003). The NFC simulation runs on a network of computers, and each participant is seated in front of a simulation computer. During the simulation, fires occur at predetermined locations and time points and participants need to use fire trucks to extinguish fires and manoeuvre bulldozers to clear land in order to prevent fires from spreading.

For this study, we based ourselves on Mathieu et al. (2001) to design scenarios that meet the main criteria of MTSs. In the scenarios, two teams were given the role of being firefighting units responsible for two neighbouring villages. Together they constituted one MTS. In addition, we manipulated the extent to which team members identified with the team and/or the MTS. Consistent with previous studies that manipulated social identification (Gonzalez \& Brown, 2003), we used vignettes, names, and differently coloured attributes to manipulate participants' identification.

Within each team, members had different roles and responsibilities. One member saw the simulated area at large, but was not privy to the details. This person was able to move vehicles, but was unable to extinguish fires or bulldoze land. Consequently, the person with this role had an overview of the situation and was responsible for locating fires and supplying the other team member with vehicles and resources. The other team member had a more detailed view of the area and was responsible for extinguishing fires and bulldozing land.

The two firefighting units were interdependent in terms of inputs, processes, and outcomes. They depended on each other for inputs as they shared a limited number of vehicles and a limited amount of resources with which to operate the vehicles (i.e., water and fuel). A team had access to either water or fuel and had the possibility of sharing resources. Fires also broke out at the border separating both villages. Thus, whenever a team failed to contain a border fire, the fire spread to the other team's village. Teams had only incomplete information regarding the location, direction, and speed of the fires across the border. Cross-team cooperation and coordination of actions were imperative to best contain these fires. MTS members were thus confronted with a trade-off, that is to either preserve the land of their own village only, or to protect the land of the MTS as a whole.

\section{Participants}

We recruited 286 students from undergraduate and graduate management courses at a Dutch University in 2010. The study was embedded in these courses as coursework material, but participation in the study was not set as a requirement necessary to pass the course nor to obtain course credits. When necessary (e.g., because of no-shows), participants were recruited in an ad boc fashion. Participants were randomly distributed over 67 four-person MTSs. Consistent with Marks et al. (2005), the MTSs consisted of two teams, each composed of two participants. Students registered electronically for participation and were assigned to MTSs randomly. We administered all relevant demographic information (e.g., gender, nationality, and game experience) during this registration process. Fifty-three per cent of the participants were female. Thirty-one per cent of the participants were Dutch, 34\% were German, and 35\% were of a different 
nationality. The three best performing teams and the three best performing MTSs received financial rewards: 60 Euros for the best team and MTS; 40 Euros for the second-best team and MTS; and 20 Euros for the third-best team and MTS.

\section{Procedure}

We used a minimal group paradigm (Tajfel, Billig, Bundy, \& Flament, 1971) to manipulate participants' team and MTS identification. On the basis of previous studies (Gonzalez \& Brown, 2003), we used vignettes, names, and differently coloured safety vests to influence participants' identification with either the team, the MTS, or with both entities. ${ }^{1}$ We considered using the four conditions that we created in the analyses. However, longitudinal analyses showed that, although initially effective, the identity manipulations were transient as the experiences that participants made during the study quickly overruled the manipulation effect. ${ }^{2}$ Therefore, we ran our analyses on the identity scores observed, and not on the conditions. In hindsight, we would argue that the manipulation of team and MTS identification still served an important purpose. This is because individuals tend to identify most strongly with the entity in which they are directly embedded (Riketta \& van Dick, 2005; van Knippenberg \& van Schie, 2000). Thus, our manipulation of participants' identification may have countered the tendency towards team identification and, thus, may have increased the sample variance in both team and MTS identification. This, in turn, may help reduce possible restriction of range problems.

Team members viewed a 10-min instruction video individually and engaged in a 10-min practice trial. The actual simulation consisted of three consecutive performance episodes, each involving a transition and an action phase (Marks, Mathieu, \& Zaccaro, 2001). In the transition phases, the two teams (i.e., four participants) were seated together around a table in the same room and were given 8 min to develop a strategy for the next action period. As input for the planning session, participants were supplied with maps, weather forecasts, and partially accurate information on the time and location of fire outbursts in the subsequent round.

Transition phases were followed by action phases. During the action phases, the two teams were located in separate rooms and participants communicated with each other via headsets. Participants were able to communicate freely within the team, but only team members with the overview role were able to communicate with the overview member of the other team. Action periods, in which participants fought the simulated fires, lasted

\footnotetext{
' In the low team - low MTS identification condition, participants were provided with four differently coloured vests and badges, read stories emphasizing individuality and personal achievement, and were instructed to come up with their own individual nickname. In the low team - high MTS identification condition, all participants were provided with the same colour vests and badges, they read stories emphasizing the glory and success of the overall fire department, and they were instructed to come up with a name for their MTS. In the high team - low MTS identification condition, participants from the two teams were provided with differently coloured vests and badges, read stories emphasizing the glory and success of the fire department of their own village, and were instructed to come up with a name for their team. In the high team - high MTS identification condition, all participants received vests of the same colour and members of the two teams received badges of different colours, they read both the stories emphasizing the past glory and success of the fire department of their own village and of the overall fire department, and they invented a name both for their team and for the MTS.

${ }^{2}$ We measured identification with the team and with the MTS four times during the study, that is after the manipulation and before each of the three trials. We used ANOVA to test whether there were significant differences between the experimental conditions in terms of MTS and team identification. Across the four time points, we obtained the following results for MTS identification: $\mathrm{t}_{l}(\mathrm{~F}=2.988, \mathrm{p}<.05), \mathrm{t}_{2}(\mathrm{~F}=1.125, \mathrm{p}>.05), \mathrm{t}_{3}(\mathrm{~F}=0.768, \mathrm{p}>.05)$, and $\mathrm{t}_{4}(\mathrm{~F}=1.135, \mathrm{p}>.05)$. For team identification, the results were as follows: $\mathrm{t}_{I}(\mathrm{~F}=6.359, \mathrm{p}<.05), \mathrm{t}_{2}(\mathrm{~F}=3.014, \mathrm{p}<.05), \mathrm{t}_{3}(\mathrm{~F}=1.901, \mathrm{p}>.05)$, and $\mathrm{t}_{4}(\mathrm{~F}=1.892, \mathrm{p}>.05)$. These results show significant effects in the expected directions at the first measurement point; these effects, however, quickly dissipated over time.
} 
$10 \mathrm{~min}$. After each action phase, participants were given a questionnaire to complete which covered our focal measures.

\section{Measures}

MTS and team identification was assessed with an established 4-item measure, developed by Doosje, Ellemers, and Spears (1995). Responses were registered on a 5-point Likerttype scale, ranging from 1 (fully disagree) to 5 (fully agree). A sample item for team identification reads: 'I see myself as a member of the team'. For MTS identification, we substituted the word 'team' for 'department'. We used the term 'department' instead of 'MTS' in the communication with the participants and in the questionnaire for the sake of clarity and brevity. The reliability for team identification for trial 1 to 3 was $.93, .96$, and .96 , correspondingly. For MTS identification, reliability was $.93, .96$, and .97 , respectively.

Interteam task and relationship conflict were both measured with a 3-item scale by Jehn and Mannix (2001). Answers were given on a 5-point Likert-type scale, ranging from 1 (none) to 5 (a lot). We adapted the scales for task and relationship conflict to fit the interteam context. A sample item for interteam task conflict reads: 'How much conflict of ideas is there between the teams in your department?' The reliability for interteam task conflict for trials 1 to 3 was $.91, .90$, and .93 , respectively. A sample item for interteam relationship conflict reads: 'How much relationship conflict is there between the teams in your department?' The reliability for interteam relationship conflict was $.82, .60$, and .78, correspondingly.

MTS performance was calculated based on the value of the land that was prevented from burning. Not every area was equally important in the simulation; therefore, each area was worth a specific amount of points. For example, more points were subtracted for burnt houses than for burnt trees. We indexed MTS performance as the percentage of points saved. We calculated this percentage as follows: Per action episode, we divided the value in points of the burnt land by the value in points of the land that could have been burnt; we reversed the resulting score, so that higher scores indicated better performance.

\section{Control variables}

Previous research suggests that the familiarity of team members influences interpersonal interaction and team performance (Binder et al., 2009; Gaertner et al., 1993). Therefore, we assessed member familiarity by a 1 -item measure, documenting participant's joint work experience. Answers were given on a 5-point Likert-type scale ranging from 1 (not at all) to 5 (extremely). Furthermore, given that we used a computer-simulated environment to test our hypotheses, participants' computer game experience might have influenced task performance (Wilson et al., 2009). We thus controlled for the number of weekly hours participants played computer games.

\section{Analytic approach}

\section{Aggregation statistics}

Aggregation statistics were calculated to validate aggregation of our constructs to the MTS

level. Table 1 provides an overview of the $r_{\mathrm{wgj}}$, ICC(1), and ICC(2) values. MTS-level consensus was estimated with the $r_{\mathrm{wgj}}$ index representing within-group agreement. All 


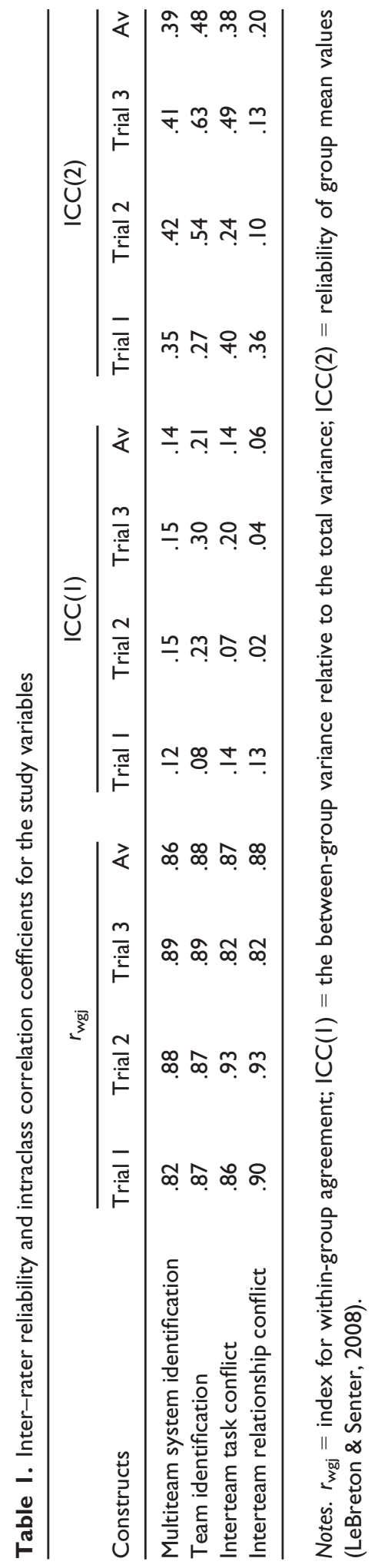


average $r_{\mathrm{wgj}}$ values for our focal constructs are well above the cut-off value of .70 generally agreed upon (LeBreton \& Senter, 2008). We also calculated intraclass correlation coefficients (ICC) to index inter-rater reliability. ICC(1) indexes the between-group variance relative to the total variance. Over the three time points, the ICC(1) varied between .06 and .21. According to LeBreton and Senter (2008), these ICC(1) values indicate reasonable evidence for group effects. ICC(2) values - indicative of the reliability of group mean values - ranged from .10 to .63 over the three time points.

ICC(2) values are a direct function of team size (Bliese, 2000); because of this fact, we assessed how ICC(2) values would change if we had larger MTSs (Brown \& Treviño, 2006). If our average MTS size was 20, our ICC(2) values would have been substantially higher, that is .75 (MTS identification), .80 (team identification), .73 (task conflict), and .50 (relationship conflict). ${ }^{3}$ In line with other scholars (Chen \& Bliese, 2002), we thus continued with the analysis, additionally because we obtained high $r_{\text {wgj }}$ values and demonstrated team-level effects. Still, given that most ICC(2) values did not reach the cutoff value of .60 suggested by Glick (1985), it may be more difficult to detect relationships between team-level variables (Bliese, 2000).

\section{Trajectories of team and MTS identification}

To assess the trajectories of team and MTS identification, we ran random coefficient models (Bliese \& Ployhart, 2002) predicting the individual team members' reported identification with the two entities at the four time points (Table 2). As can be seen from Model 1 in Table 2, the MTS identification manipulation was initially negatively and the team identification was positively related to team identification. In addition, time had a positive effect on team identification, and the interaction between time and the team identification manipulation was negative, indicating that the manipulation became less effective over time. As can be seen in Table 2, the MTS identification manipulation was

Table 2. Results of random coefficient models predicting team identification and multiteam system (MTS) identification over time

\begin{tabular}{lcc}
\hline & Model I (team identification) & Model 2 (MTS identification) \\
\hline Intercept & $1.63^{* * *}(0.10)$ & $0.57^{* * *}(0.12)$ \\
Team identification & & $0.68^{* * *}(0.02)$ \\
MTS identification & $0.60^{* * *}(0.02)$ & \\
MTS id. manipulation & $-0.19^{*}(0.08)$ & $0.33^{* * *}(0.09)$ \\
Team id. manipulation & $0.38^{* * *}(0.08)$ & $-0.25^{* *}(0.09)$ \\
Boundary spanner & $-0.12(0.08)$ & $0.23^{* *}(0.08)$ \\
Time & $0.09^{*}(0.03)$ & $0.07^{*}(0.03)$ \\
Time*MTS id. manipulation & $0.04(0.03)$ & $-0.05(0.03)$ \\
Time*Boundary spanner & $0.01(0.03)$ & $0.02(0.03)$ \\
Time*Team id. manipulation & $-0.07^{*}(0.03)$ & $0.06^{\dagger}(0.03)$ \\
\hline
\end{tabular}

Notes. $n=I, 108$ (identification measurement points), ${ }^{* * *} p<.001 ; * * p<.01$; $*_{p}<.05 ; \dagger p<.1$. Boundary spanner $(0=$ non-leader, $I=$ team leader $)$. MTS id. manipulation $=$ MTS identification manipulation; Team id. manipulation $=$ Team identification manipulation.

\footnotetext{
${ }^{3}$ To simulate the ICC(2) values for an MTS size of 20, we used the Spearman-Brown formula (Bliese, 2000).
} 
initially positively and the team identification manipulation was negatively related to MTS identification. In addition, time had a positive effect on MTS identification, and the negative effect of the team identification manipulation decreased over time. Finally, the results showed that being a boundary spanner (i.e., team leader) was positively related to MTS identification and that the interaction between being a boundary spanner and time was not significant, indicating that this effect was stable over time.

\section{Random coefficient modelling}

We also used random coefficient modelling (RCM) to test our hypotheses (Bliese \& Ployhart, 2002). RCM offers advantages over regular statistical analyses such as hierarchical linear regression or repeated-measures ANOVA. RCM accounts for the nonindependence of observations as given in a repeated-measures design (Bliese, 2000). Additionally, RCM accounts for inconsistent variances, provides tests of intra- and interteam changes, and allows intercepts (e.g., initial status) and slopes (i.e., rate of change) to vary across MTSs (Bliese \& Ployhart, 2002). Recent examples are in Chen et al. (2009) and Chen and Mathieu (2008).

We estimated our growth models by means of the Non-linear and Linear Mixed Effects (NLME) program for R (version 2.13), an open-source statistical software well suited for RCM (Culpepper \& Aguinis, 2011). We coded time as 0, 1, and 2 to represent trial 1, trial 2, and trial 3 . In this way, we were able to interpret the intercept of our performance growth model as the overall MTS performance on the first trial (Bliese \& Ployhart, 2002). We grand-mean-centred our dependent and independent variables to ease interpretation and enable cross-model comparison (Singer \& Willett, 2003).

\section{Results}

The descriptive statistics and zero-order correlations among the study variables are depicted in Table 3. Mean values of overall MTS performance ranged from $47.82 \%$ to $82.35 \%$ of saved land. Furthermore, bivariate correlations indicated a negative association overall between MTS performance and interteam (task and relationship) conflicts. We also found (MTS and team) identification to associate with interteam conflict negatively.

To test whether MTS identification, team identification, and interteam task and relationship conflict exhibited sufficient convergent and discriminatory validity, we performed a series of confirmatory factor analyses (CFA) at the MTS level. For all three trials, we found the 4-factor model was a better fit to the data than the 2- or 1-factor model. Therefore, we retained the 4 -factor solution for all subsequent analyses. The fit indices for the different models can be found in Table 4 .

\section{Modelling trajectories}

We measured our focal constructs at three points in time and followed Bliese and Ployhart (2002) in constructing our growth model for overall MTS performance. As a baseline model, we use a regression model with fixed intercept and fixed slope. We used restricted maximum likelihood (REML) for parameter estimation. Accordingly, we only relied on deviance statistics ( $-2 \log$-likelihood ratio test statistic) to test for differences in model fit when the models did not differ in the fixed part (Hox, 2010). 


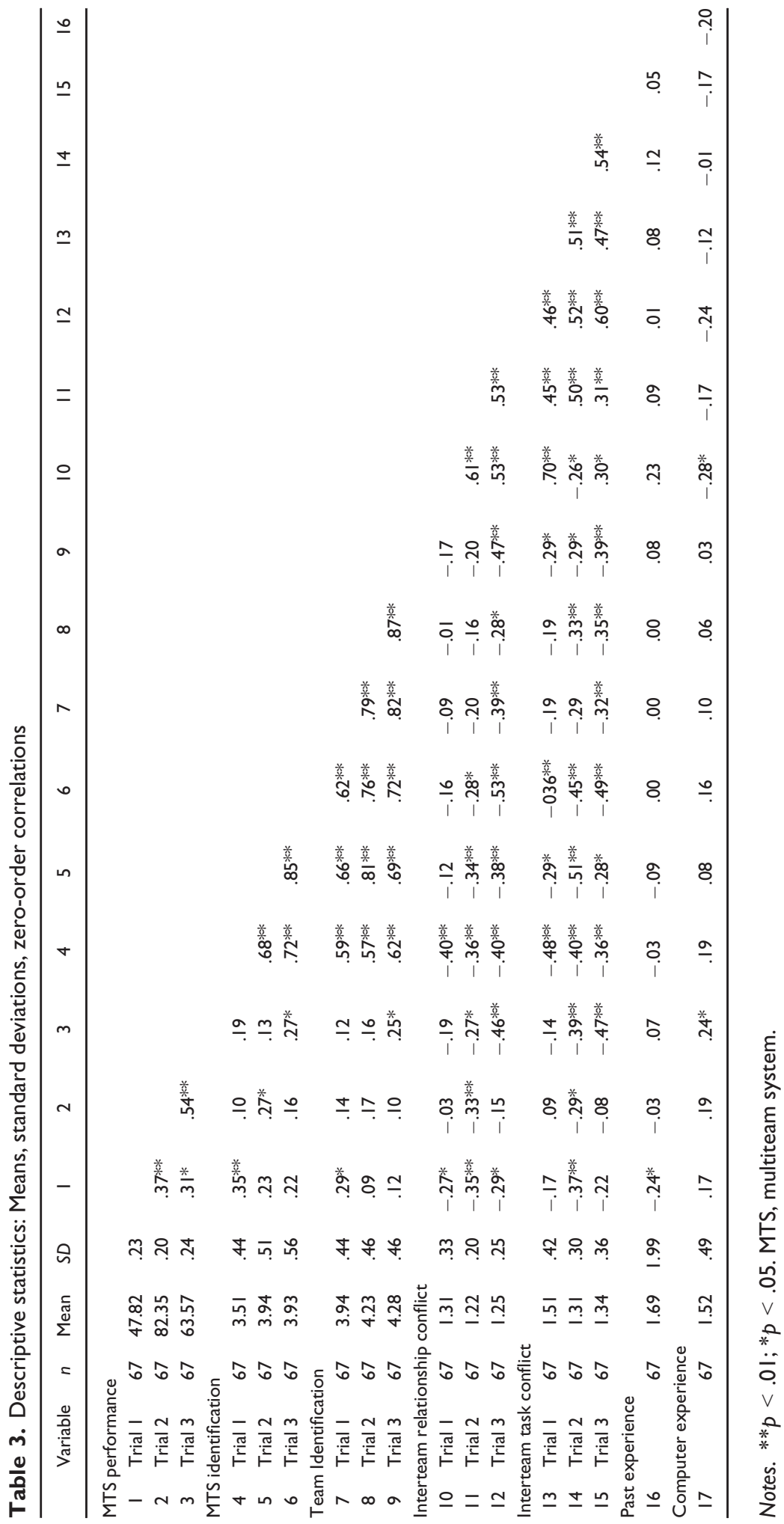


Table 4. Results of confirmatory factor analysis

\begin{tabular}{lcccc}
\hline Model & $\chi^{2 *}(\mathrm{df})$ & CFI & SRMR & RMSEA** \\
\hline Four-factor model & & & & .08 \\
Trial I & $100.75(66)$ & .96 & .06 & .09 \\
Trial 2 & $105.70(66)$ & .96 & .05 & .13 \\
Trial 3 & $142.00(66)$ & .93 & .05 & .18 \\
Two-factor model & & & & .15 \\
Trial I & $217.13(71)$ & .82 & .15 & .21 \\
Trial 2 & $184.01(71)$ & .88 & .08 & .25 \\
Trial 3 & $285.37(71)$ & .81 & .14 & .22 \\
One-factor model & & & .22 & .28 \\
Trial I & $381.13(72)$ & .61 & .15 & .17 \\
Trial 2 & $314.51(72)$ & .74 & .67 &
\end{tabular}

Notes. $* \chi^{2}$ is significant at $p<.001$.

**Please note that RMSEA tends to incorrectly falsify models based on an increased RMSEA when sample size is relatively small (Hu \& Bentler, 1999; Kenny, Kaniskan, \& McCoach, 20I3).

\section{Intraclass correlation coefficient}

The first step in building a random coefficient model is the calculation of ICC(1) for MTS performance across the three measurement points. In this context, the ICC(1) is the variance of MTS performance over time that is attributable to between-MTS differences rather than within-MTS differences (Bliese \& Ployhart, 2002). Analyses revealed that ICC (1) for MTS performance was .16, indicating that between-MTS variance explained $16 \%$ of the variance in performance across the three measurement points in time. According to Bliese (2000), this value signifies considerable differences in MTS' performance trajectories. From this, we conclude that the estimation of more complex models to examine longitudinal change in performance is justified. For interteam task and relationship conflict, the ICC(1) was .44 and .50 , respectively. Growth modelling is thus also justified for these constructs.

\section{Building a growth model}

The next step is to examine whether a random intercept model (i.e., MTSs differ substantially in their initial performance levels) fits our data better than a fixed intercept model. Next, we compared the fit of a random slope model (i.e., MTSs differ substantially in the way their performance changes over time) with the fit of the random intercept model. We used deviance tests and calculated chi-square differences to establish the optimal model. Results of these analyses indicate the random intercept model fit the data significantly better than the baseline model $\left(\Delta 2 \mathrm{LL}^{4}=4.405, p<.05\right)$. The random slope model did not significantly improve upon the random intercept model $(\Delta 2 \mathrm{LL}=0.00$, $p>.1$ ). This implies that, in our data, a model that only accounts for performance differences between MTSs at the start of the study provides a better fit than a model in which the rate of change also varies across MTSs. In other words, we can infer from this that the slope identified can be generally applied to all MTSs equally well.

\footnotetext{
${ }^{4}-2$ LL stands for log-likelihood ratio test statistic.
} 
Accordingly, we use a random intercept fixed slope model for testing our hypotheses (Bliese \& Ployhart, 2002). Before analysing our hypotheses, we tested for autocorrelation $(-2 \mathrm{LL}=-10.91)$ and heteroscedasticity $(-2 \mathrm{LL}=-10.89)$. Autocorrelation indicates that observations close in time correlate more strongly with each other than observations distant in time (Bliese \& Ployhart, 2002); heteroscedasticity would imply that the variance in the observations increased or decreased substantially over time (Bliese \& Ployhart, 2002). The model in which we controlled for autocorrelation yielded an improved fit relative to our data $(\Delta 2 \mathrm{LL}=4.58, p<.05)$, whereas the model controlling for heteroscedasticity did not improve model fit $(\Delta 2 \mathrm{LL}=0.03, p>.1)$. We therefore controlled for autocorrelation in all further analyses.

The final estimates of the fixed effects of the growth model show that, at the start of the study, the predicted overall level of MTS performance was 47.82 , which then increased by .08 at each subsequent performance episode. In other words, we found a positive and linear trend for the influence of time on MTS performance (Estimate $=.08$ (.02), $p<.001)$.

Concerning interteam task conflict, we found a random intercept fixed slope model to best fit the empirical data $(\Delta 2 \mathrm{LL}=39.82, p<.001)$. For interteam relationship conflict, we found evidence for substantial variability in the intercept $(\Delta 2 \mathrm{LL}=48.24, p<.001)$, as well as for variability in the rate of change $(\Delta 2 \mathrm{LL}=9.89, p<.001)$; model fit further improved when autocorrelation was controlled for $(\Delta 2 \mathrm{LL}=17.5, p<.001)$.

\section{Time-varying predictors of MTS performance}

Hypothesis 1a predicts that MTS identification is positively related to overall MTS performance, and Hypothesis 1b states that this relationship is moderated by team identification. As can be seen from Model 1 in Table 5, MTS identification exhibits a positive relationship with overall MTS performance $(\pi=.15, p<.01)$, supporting Hypothesis 1a. However, neither the direct effect of team identification nor the interaction effect of MTS identification and team identification has an effect on MTS performance. So, no evidence is found for Hypothesis $1 \mathrm{~b}$. To estimate the effect size of these predictors, we calculated pseudo $R^{2}$ statistics (Singer $\&$ Willett, 2003). This statistic is based on the relative reduction of the residual variance when comparing a model with predictors to a baseline model. Adding MTS and team identification to the model amounts to a pseudo $R^{2}$ of .14 , indicating that $14 \%$ of the within-MTS variance in overall performance is explained by identification at the MTS level.

Hypotheses $2 \mathrm{a}$ and $2 \mathrm{~b}$ predict that MTS identification will be negatively related to interteam relationship and task conflict. As can be seen from Model 4 and Model 5 in Table 5, MTS identification shows an overall negative association with interteam task conflict $(\pi=-.43, p<.001)$ as well as with relationship conflict $(\pi=-.32, p<.001)$. Hypothesis 2 was therefore supported. Hypotheses $3 \mathrm{a}$ and $3 \mathrm{~b}$ predict that team identification will moderate the relation between MTS identification and both interteam relationship and task conflict. As can be seen from Model 4 and Model 5, the analysis only revealed a positive interaction for the fixed effect of team and MTS identification on both interteam task $(\pi=.17, p<.05)$ and relationship conflict $(\pi=.19, p<.05)$. To attain a better understanding of what these interaction effects imply, we plotted these effects. As can be seen in Figure 2, MTSs with high MTS identification experience less interteam relationship and task conflict than MTSs with low MTS identification. However, team identification partially counters this intercept effect in that the negative relationship between MTS identification and task and relationship conflict is stronger when team 
Table 5. Results of main effect models predicting overall multiteam system (MTS) performance (I-3) and interteam task (4) and relationship conflict (5)

\begin{tabular}{|c|c|c|c|c|c|}
\hline $\begin{array}{l}\text { Predictors } \\
\text { Fixed effects }\end{array}$ & $\begin{array}{c}\text { Model I } \\
\text { Estimate (SD) }\end{array}$ & $\begin{array}{c}\text { Model } 2 \\
\text { Estimate }(S D)\end{array}$ & $\begin{array}{c}\text { Model } 3 \\
\text { Estimate (SD) }\end{array}$ & $\begin{array}{c}\text { Model } 4 \\
\text { Estimate }(S D)\end{array}$ & $\begin{array}{c}\text { Model } 5 \\
\text { Estimate }(S D)\end{array}$ \\
\hline (Intercept) & $.61 * * *(0.03)$ & $.61 * * *(0.03)$ & $.61^{* * * *}(0.03)$ & $-.02(0.04)$ & $-.03(0.04)$ \\
\hline Time & $.04 *(0.02)$ & $.04^{\dagger}(0.02)$ & $.04^{\dagger}(0.02)$ & $-.01(0.02)$ & $.01(0.02)$ \\
\hline Past experience & $-.01(0.04)$ & $.00(0.04)$ & $.00(0.04)$ & $.05(0.07)$ & $.01(0.05)$ \\
\hline Computer games & $.02(0.01)$ & $.01(0.01)$ & $.01(0.01)$ & $-.01(0.02)$ & $-.02^{\dagger}(0.01)$ \\
\hline MTS identification & $.15 * *(0.05)$ & $.09(0.06)$ & $.09(0.05)$ & $-.43 * * *(0.07)$ & $-.32 * * *(0.07)$ \\
\hline Team identification & $.06(0.06)$ & $.08(0.06)$ & $.09(0.06)$ & $.12(0.08)$ & $.22 * *(0.08)$ \\
\hline $\begin{array}{l}\text { MTS identification: } \\
\text { Team identification }\end{array}$ & $-.01(0.06)$ & $.02(0.06)$ & $.01(0.06)$ & $.17^{*}(0.08)$ & $.19 *(0.09)$ \\
\hline Task conflict & & $-.16 * *(0.06)$ & & & \\
\hline Relationship conflict & & & $-.22 * *(0.08)$ & & \\
\hline $\begin{array}{l}\text { Time: MTS } \\
\text { identification }\end{array}$ & & & & & $.04(0.04)$ \\
\hline $\begin{array}{l}\text { Time: Team } \\
\text { identification }\end{array}$ & & & & & $-.12 *(0.05)$ \\
\hline $\begin{array}{l}\text { Time: MTS: Team } \\
\text { identification }\end{array}$ & & & & & $-.02(0.06)$ \\
\hline $\begin{array}{l}\text { Predictors } \\
\text { Random effects }\end{array}$ & $\begin{array}{l}\text { Model I } \\
\text { (Variance) }\end{array}$ & $\begin{array}{c}\text { Model } 2 \\
\text { (Variance) }\end{array}$ & $\begin{array}{l}\text { Model } 3 \\
\text { (Variance) }\end{array}$ & $\begin{array}{c}\text { Model } 4 \\
\text { (Variance) }\end{array}$ & $\begin{array}{c}\text { Model } 5 \\
\text { (Variance) }\end{array}$ \\
\hline $\begin{array}{l}\text { Level I: Within-MTS } \\
\text { variance }\end{array}$ & $0.04 * *$ & $0.04 * *$ & $0.04 * *$ & $0.06 * *$ & 0.04 \\
\hline Level 2: In intercept & $0.02 * *$ & $0.02^{* * *}$ & 0.01 *** & $0.05^{* *}$ & 0.04 \\
\hline In slope & & & & & 0.01 \\
\hline Covariance & & & & & -0.02 \\
\hline \multicolumn{6}{|l|}{ Goodness of fit } \\
\hline-2 log-likelihood & 19.69 & 15.87 & 15.03 & 103.98 & 16.85 \\
\hline $\mathrm{AIC}$ & 38.41 & 36.67 & 35.82 & 121.98 & -5.70 \\
\hline $\mathrm{BIC}$ & 70.67 & 72.10 & 71.25 & 151.39 & 39.83 \\
\hline
\end{tabular}

Notes. $n=67$. For establishing significance of random effects, we constructed confidence intervals at the $95 \%$ and $99 \%$ levels (Field, Miles, \& Field, 2012). ${ }^{* * *} p<.001 ; * * p<.01 ; * p<.05 ; \dagger p<.1$.

identification is low than when team identification is high. To sum up, we do find an interaction effect, but this effect is the opposite of what we expected. Therefore, hypotheses $3 \mathrm{a}$ and $3 \mathrm{~b}$ are not supported.

Furthermore, our findings show a positive overall effect overall of team identification on the intercept of interteam relationship conflict $(\pi=.22, p<.01)$. Each unit-increase in team identification is related to an increase of .22 units in interteam relationship conflict. Additionally, team identification is negatively related to the rate of change of interteam relationship conflict $(\pi=-.12, p<.05)$. This implies that the positive relationship between team identification and interteam relationship conflict becomes weaker over time. When we add MTS and team identification as predictors to the random intercept growth models, a pseudo $R^{2}$ of .24 for interteam relationship conflict and .20 for interteam task conflict is the result. 


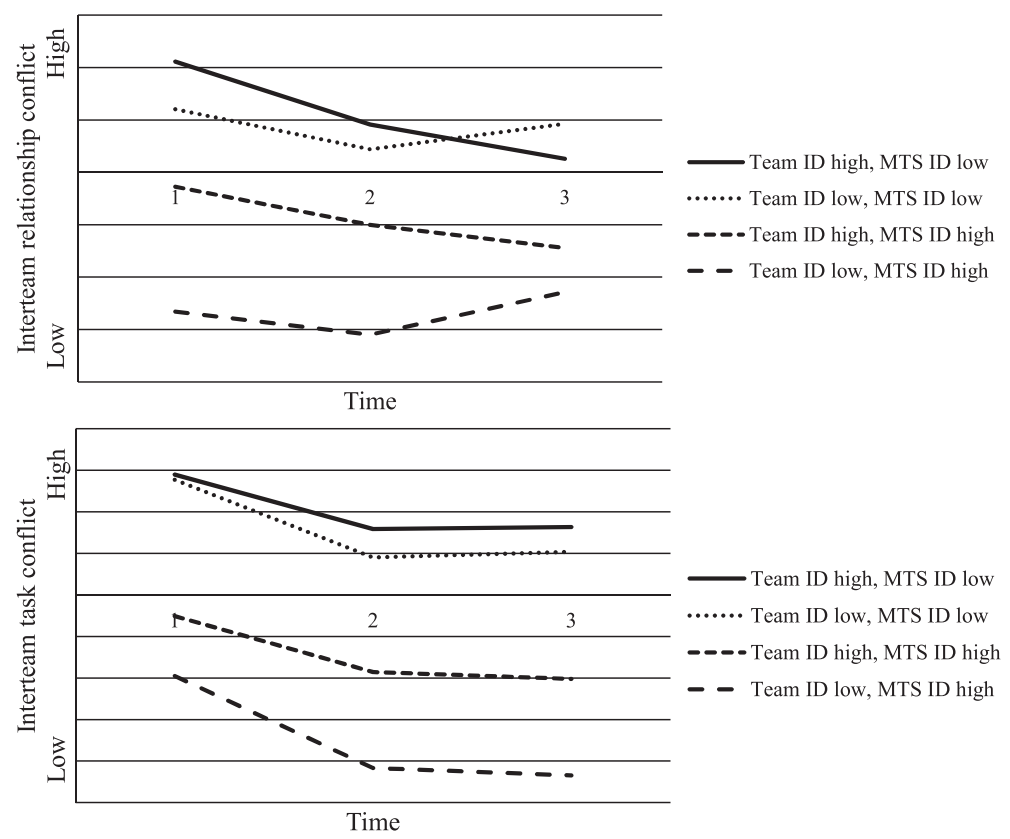

Figure 2. Interaction effect multiteam system (MTS) and team identification on interteam task and relationship conflict. Note. We operationalized high and low team and MTS identification using I SD above and I SD below the mean of the self-reported identification measures.

Hypotheses $4 \mathrm{a}$ and $4 \mathrm{~b}$ stated that interteam relationship and task conflict will be negatively related to MTS performance respectively. Indeed, as can be seen from Model 2 and Model 3, we found both relationship conflict $(\pi=-.22, p<.01)$ and task conflict $(\pi=-.16, p<.01)$ to associate with overall MTS performance negatively. When we add interteam relationship and task conflict to the random intercept model, this results in pseudo $R^{2}$ values of .03 and .04 , respectively. Finally, hypotheses $5 \mathrm{a}$ and $5 \mathrm{~b}$ suggested mediation effects of interteam relationship and task conflict. To test these mediation effects, we extended the mediation framework of Baron and Kenny (1986) to fit a longitudinal framework, and we followed the multiple step approach as suggested by Kenny, Korchmaros, and Bolger (2003). Firstly, we calculated the unmediated effect path from MTS and team identification on overall MTS performance (see Hypothesis 1). Secondly, we calculated the paths from the independent variable to the mediators, that is the paths from MTS identification to interteam task and relationship conflict (see Hypothesis 2 and Hypothesis 3). Thirdly, we simultaneously tested the pathway from the mediating variable to the outcome variable and from the independent variable(s) to the outcome variable. To assess a mediation effect, the unmediated path should substantially reduce in strength or become insignificant when entering the mediating variable. As can be seen in Model 2 and Model 3, the association between MTS identification and MTS performance becomes insignificant when interteam relationship and, subsequently, task conflict are added to the equation. The link between interteam task and relationship conflict to overall MTS performance becomes significant (see Hypothesis 4).

To examine this mediation effect further, we used the Monte Carlo method which, according to Preacher and Selig, may be 'the only viable method' (2012, p. 94) to assess indirect effects in a multilevel context. Using Selig and Preacher's (2008) interactive tool, 
we constructed confidence intervals for the indirect effect. The $99 \%$ confidence interval of the indirect effect for interteam task conflict excludes zero (lower bound: 0.001, upper bound: 0.151). This indicates a significant indirect effect for interteam task conflict. The 99\% confidence interval of the indirect effect for interteam relationship conflict also excludes zero (lower bound: 0.005 , upper bound: 0.163 ). This also indicates a significant indirect effect for interteam relationship conflict. From this, we can conclude that both interteam task conflict and interteam relationship conflict mediate the association between MTS identification and overall MTS performance. Hypotheses 5a and 5b are thus supported.

\section{Discussion}

In this study, we investigated how MTS and component team identification interactively influence interteam conflict and MTS performance. We find evidence that MTS identification tempers interteam task and relationship conflict. Both kinds of interteam conflict, we find, are negatively related to MTS performance. In accordance with previous research on multiple identities, we find that identification with both the lower and the higher entity is important for team processes and performance (Hornsey \& Hogg, 2000). However, in contrast to previous studies (Richter et al., 2006), we do not find evidence for the positive effect of dual identification. We find MTS identification to be more important for reducing conflict when team identification is low than when team identification is high. Moreover, we find that although team identification initially causes interteam relationship conflict, this association weakens over time.

\section{Theoretical implications}

Our findings extend the research into the effects of dual identification on multiteam processes and performance. To date, only a few empirical studies exist that have examined MTS processes and outcomes (Davison et al., 2012; DeChurch \& Marks, 2006; Firth et al., 2015; Marks et al., 2005). These studies have greatly increased our understanding of MTSs, but they did not assess the simultaneous effects of MTS and team identification on MTS processes and performance. Our study addresses this void. We assess the combined effects of team and MTS identification on MTS performance, while accounting for the mediating role of interteam conflict. The results of our longitudinal analysis demonstrate that MTS identification has a beneficial effect on performance, whereas team identification increases interteam conflict and negatively influences MTS performance.

In their overview on the state-of-the art of MTS research, DeChurch and Zaccaro (2010) posit that research on affective emergent states, such as identification, is an important precondition of moving this field forward. Referencing resource allocation theory (Kanfer \& Ackerman, 1989), DeChurch and Zaccaro (2010) also suggest that, importantly, identification with an entity determines the extent of resources that an individual invests in attaining the goals of that particular entity. Our findings on the positive effect of MTS identification on MTS performance support this notion: The more members identify with an MTS, the more effort they are likely to invest in reaching the goals of that MTS, and consequently, the more likely it is that these goals will be attained.

Our results have implications for social identification research, most especially because empirical studies into the relationship between social identification and 
intergroup conflicts in MTS settings are rare (for an exception, see Richter et al., 2006). Our findings that MTS identification keeps interteam relationship and task conflict at bay addresses this empirical gap in the research and, empirically, confirm prior studies on the common ingroup identity model (Gaertner et al., 1993). The common ingroup identity model indicates that when team members identify with an overarching team instead of with a component team, ineffective intergroup relations (intergroup bias and conflict) can be transformed into effective ones (Dukerich, Golden, \& Shortell, 2002; Gaertner et al., 1999). That we did not find evidence for any effect of dual identification on performance aligns with the literature which points out the contextual specificity of the effectiveness of maintaining a dual identity (Gaertner, Dovidio, \& Bachman, 1996). Gaertner et al. (1996) found desirable effects of dual identities in an interracial education setting, but not in a bank merger.

Although MTS identification is negatively associated with interteam conflict, this effect is stronger when team identification is low rather than high. This speaks against a model of identification in which high MTS identification would reduce the negative effects of high team identification. Instead, our results suggest that the effects of MTS identification depend on the level of identification with the team. Social identification is driven by the need for positive self-affirmation and uncertainty reduction (Abrams \& Hogg, 1988). The relative importance of MTS identification may therefore depend on the extent to which team identification can help reduce uncertainty. To the extent that team identification does not help members to reduce uncertainty, MTS identification becomes important. When MTS identification is highly salient for members' uncertainty reduction and selfconcept, the goals and values of the MTS will be highly valued, making interteam conflict less likely.

In comparison with Richter et al. (2006), we find interteam conflict to be higher when both team and MTS identification are high, compared to situations where only MTS identification is high. Richter et al. (2006) established that MTS and team identification would both jointly reduce interteam conflicts, in alignment with optimal distinctiveness theory (Brewer, 1991). Our results, however, appear more consistent with the common ingroup identity model of Gaertner et al. (1993). Gaertner et al. (1993) argue that intergroup conflict and bias are driven both by the motivation to enhance ingroup status and the motivation to devalue outgroup status. Although MTS identification reduces the tendency to devalue the other team (i.e., the outgroup), high team identification still motivates team members to emphasize the superiority of their own team, which may cause interteam friction.

It is possible that our results differ from Richter et al. (2006) because of differences in context. Whereas we assessed the extent to which members identified with a fourmember multiteam system, Richter et al. (2006) focused on health care organizations employing several hundreds of workers. It may well be that the likelihood of feeling 'overincluded' was larger in their study given that the large health care organizations were more abstract and thus offered less possibility for feeling unique than the MTSs in our study. As Hogg and Terry (2000) noted, externally imposed assimilation is particularly likely to lead to identity threat 'where the superordinate group is very large, amorphous, and impersonal' (p. 131). In contrast, when the superordinate entity is more concrete and relatively small in size, and when members regularly interact with their colleagues, identity threat due to a loss of sense of uniqueness is less likely to occur. From this, it follows that optimal distinctiveness theory may hold in large amorphous organizations, whereas common ingroup identity theory may be more suitable in explaining identity dynamics in smaller concrete entities. Although this explanation seems to reconcile the 
findings of our study with the results from Richter et al. (2006), further research is necessary to confirm this explanation.

As our results indicate, the positive association between team identification and interteam relationship conflict diminishes over time. This finding corresponds with Allport's (1954) contact hypothesis, according to which intergroup contact is one of the most effective ways to reduce intergroup bias. The contact hypothesis suggests that when the appropriate conditions are in place - such as equal status between groups, cooperative intergroup interactions, and opportunities for attaining personal acquaintance with outgroup members - the opportunity to interact with others increases understanding and appreciation for their perspective, which improves intergroup relationships. Further supporting evidence for this hypothesis can be seen in our analyses depicting the development of MTS and team identification over time. Results demonstrate that identification with both the MTS and the team increases over time. This suggests that when team members have time to get to know each other and to cooperate, their attachment with the entities they are part of is likely to increase. Furthermore, the finding that boundary spanners have higher MTS identification than non-boundary spanners also corroborates the contact hypothesis. Richter et al. (2006) demonstrated that boundary spanners who strongly identified with both their work group and their organizations were confronted with fewer conflicts between groups and enjoyed higher group performance. Hence, the diminishing positive effect of team identification on interteam relationship conflict may also stem from team boundary spanners who act as a role model (Conger \& Kanungo, 1987), setting the stage for high-quality intergroup relationships (Hogg et al., 2012). To investigate the mechanisms behind these dynamics, future research is necessary.

\section{Limitations and directions for future research}

The fact that we relied on students fighting a simulated fire in the laboratory limits the generalizability of our findings. However, we were primarily interested in assessing how basic psychological processes (i.e., social identification) influence interteam conflict and MTS performance. In other words, our primary interest was in ensuring psychological realism, not mundane reality (Marks, 2000). To provide a psychologically robust test of our hypotheses, we relied on widely accepted experimental designs and manipulation materials. We argue that such laboratory studies are especially important to the advancement of MTS research, given that MTS research is still in its beginnings and many of the basic mechanisms of multiteam performance are yet to be discovered. Nonetheless, we call for field studies to validate our experimental findings.

We manipulated the extent to which team members identify with both the team and MTS by means of a minimal group paradigm. As evident from the manipulation check, our experiment successfully captured different combinations of identification common in real-world settings; however, the effects of the manipulations proved to be transient. Although the minimal group paradigm is successfully and widely implemented in psychological experiments (Gaertner et al., 1996, 1999; Giessner \& Mummendey, 2008), our results suggest that such artificially created identifications may not hold over time. Recent research suggests that identification processes are deeply embedded in the history and interpersonal interactions of organizational members (Fiol, Pratt, \& O'Connor, 2009). Thus, we see a chance for future research to assess how identification influences interteam conflicts among teams who have a more substantial past compared to temporary MTSs. For example, although we found tentative evidence that interteam 
contact reduces initial differences in experienced interteam relationship conflict, these initial differences might be less easily resolved if identities are more deeply embedded in long-term organizational interactions (Binder et al., 2009).

In moving forward, and related to this issue, we see a strong need for 'temporal theorybuilding and empirical research' (Roe, Gockel, \& Meyer, 2012, p. 630) in the MTS literature. In spite of repeated calls in the organizational behaviour literature (Ancona, Goodman, Lawrence, \& Tushman, 2001; Arrow, Poole, Henry, Wheelan, \& Moreland, 2004), we still miss process-oriented, temporal theories in MTS research that would allow for a description of how and why, for example, identification, conflict, and performance co-evolve over time. We believe that contact hypothesis holds great potential for temporal theorizing on MTSs and, thus, encourage future research to go in this direction. We also believe that by taking time more seriously, it would become possible to help leaders of MTSs to decide on when they should intervene and mediate in a conflict between teams (Hackman \& Wageman, 2005; Roe et al., 2012).

Next, one may speculate that some of our non-significant findings were due to the rather low ICC(2) values for our main model variables (Srivastava, Bartol, \& Locke, 2006). Although we cannot completely rule out the possibility that the low ICC(2) values may have influenced our tests, we have good reason to believe that any corresponding bias should be relatively marginal. Firstly, we demonstrated that the low ICC(2) values are, at least partially, due to the small number of respondents per team in our study (Bliese, 2000). Secondly, we established high inter-rater agreement (i.e., $r_{\text {wgj }}$ values) for our main model variables and reasonable evidence for MTS effects. Thirdly, we defined all of our substantive measures at the MTS level and used referent-shift items appropriate for the study of higher unit phenomena (Chan, 1998; Klein, Conn, Smith, \& Sorra, 2001).

Furthermore, our findings may not necessarily generalize to other contexts and MTSs and this is mainly for two reasons. One reason is that the members of the MTSs investigated in our study needed to perform tasks that might have been less complex and less diverse than the work of other MTSs. For instance, we expect our findings to hold for other MTSs that have a divisional structure (i.e., component teams who have rather similar tasks but work in different geographical areas); our findings, however, may not fully apply to MTSs composed of highly differentiated and specialized component teams (e.g., disaster response MTSs composed of teams of charitable organizations such as the Red Cross and teams from the military; DeChurch et al., 2011). We also did not speak to MTSs that routinely have no opportunity to meet and prepare their actions, such as the case with disaster response MTSs that combat the effects of earthquakes or tornados (DeChurch et al., 2011). Our findings, however, should still be meaningful to those disaster response MTSs that do have some time for preparation, such as when fighting hurricanes; hurricanes can be and often are detected hours or days before reaching land (DeChurch et al., 2011).

Another reason is that we assumed each member to belong to only one MTS component team. Although this may well be the case for most emergency response and firefighting systems (O'Leary, Woolley, \& Mortensen, 2012), it may not hold for other kinds of MTSs, such as design and production environments. For instance, in airplane production, senior engineers may simultaneously be members of different design teams, such as cabin, fittings, and fuselage teams (O'Leary et al., 2012). Such multiple team membership, although fraught with identity-related tensions at the intrapersonal level (O'Leary, Mortensen, \& Woolley, 2011), may actually help alleviate interteam biases and conflicts. This is because multiple team membership may make team boundaries more 
permeable, which may prompt members to form ingroup relationships with other teams. However, until future research becomes available, this suggestion remains speculative.

In moving forward and in addressing these issues, we see a chance for empirical research into larger, interfunctional MTSs composed of teams that are interdependent, not only in terms of non-human resources (e.g., equipment, machinery), but also in terms of human resources (i.e., employees). Examples of such highly complex and interdependent MTSs have been documented, but hardly studied, and these include MTSs securing large-scale public events such as the Olympics (Goodwin, Essens, \& Smith, 2012), MTSs developing and launching products such as drugs (Marks \& Luvison, 2012), and MTSs responsible for managing emergency operations in response to unexpected safety crises (Uitdewilligen \& Waller, 2012). Any of these examples would make an appropriate context for designing field studies that allow the different kinds of interdependencies (including multiple team membership) in MTSs to be captured.

An alternative for the integration of multiple identities might be the relational identities model (Hogg et al., 2012). This model implies that group members should be able to define themselves in terms of the relationship that exists between their own group and the group with which they are collaborating. Thus, group members should be able to feel both distinct and valued at the same time and keep intergroup conflict at bay. Hogg et al. (2012) suggest intergroup collaboration be facilitated by creating an identity among group members that resides at the intergroup level: The creation of a sense of belonging that does not only reside in being similar, but also in being different from the people with whom one cooperates. Effective intergroup leadership is considered a crucial determinant for the creation of an intergroup identity. This might be especially valuable for fostering collaboration in large firms composed of multiple business units, where each business unit may be considered an organizational entity in itself (Albert \& Whetten, 1985).

\section{Practical implications}

Our results stress the importance of MTS identification for limiting interteam conflict and improving performance. MTSs are often short-lived in that members only work together for a limited period of time, such as when developing a product or containing an emergency (Mathieu et al., 2001). Hence, members may not have any experience in working together and may not easily identify with the overall collective. Therefore, managers should engage in practices that help MTS members to identify with the collective more quickly. For instance, previous research has shown that using common cultural values, signs, and symbols, individuals quickly create an overarching identity (Giessner \& Mummendey, 2008). Similarly, MTS identification could be fostered by linking MTSs to people's higher level norms and values, for example members' professional motivation (Eisenbeiss \& Otten, 2008). For example, in MTSs consisting of teams from various emergency management organizations, reference to their identity as 'emergency workers' and the establishment of cross-functional communities of practice (Uitdewilligen \& Waller, 2012) facilitate rapid identification with the MTS.

Our results show that strong identification with the component teams increases interteam conflict and reduces MTS performance. In practice, strong team identification may be especially likely given two conditions. Firstly, when teams rarely collaborate in an MTS context, team members may identify significantly more with the team than with the MTS, simply because they are more exposed to the team than the MTS (van Knippenberg \& van Schie, 2000). Secondly, when members within the component teams are more 
similar to each other than to members of the other teams in the MTS, they are likely to identify more strongly with their component team. This is especially likely in the case of an MTS where teams stem from different organizations, and this is likely to result in high between-group and low within-group diversity on a variety of characteristics, such as demographics and functional background. As strong identification with the component teams may cause interteam conflict, managers may design MTSs in such a way that interteam differences are reduced. We do not mean to say that managers should seek to reduce team identification, but we caution managers not to invest in team identification alone, because this may inadvertently harm the members' collective identification with the overall MTS (DeChurch et al., 2011). Instead, managers should try to identify means by which they can help members of different teams to work together productively (even without having much prior joint work experience). As already pointed out by Marks et al. (2005), it remains quite a challenge for leaders to find this balance between MTS- and teamlevel processes. To address this substantial challenge, leaders may possibly want to build superordinate goals that integrate the teams' individual goals and values (Fiol et al., 2009). This integration may be even more important when MTS- and team-level goals are strategically non-aligned. In such situations, emphasizing team identification may unnecessarily thwart employees' efforts to obtain the higher level MTS' goals. We hope that these recommendations help practitioners make use of this progressive organizational form in more effective ways.

To conclude, although MTS research is beginning to accumulate, hardly any attention has been paid to how trade-offs in goal preferences (i.e., MTS identification vs. team identification) influence MTS performance. Similarly, we know relatively little about the mechanisms that may explain this relationship. Our theoretically grounded study (Hornsey \& Hogg, 2000; Kanfer \& Ackerman, 1989; Richter et al., 2006; van Dick et al., 2008) provides novel insights into these under-researched but important issues, and given that basically any MTS will need to deal with trade-offs in goals, the potential and the necessity for future research in this area are vast.

\section{Acknowledgements}

We are grateful for the valuable feedback received when presenting earlier versions of this paper at the 5 th Annual INGRoup (Interdisciplinary Network for Group Research) Conference, 22-24, July 2010, Washington, DC, the Network of Social Innovation (NSI) Seminar at Maastricht University, and the Academy of Management Conference, 12-16 August 2011, San Antonio, Texas, United States. We acknowledge the help of Elena Stamova, Julia Koch, Julia Nocker, Carolin Pfeifer, and Viktoria Müller in data collection. This research was supported in part by a grant from the Network of Social Innovation (NSI), Maastricht University.

\section{References}

Abrams, D., \& Hogg, M. A. (1988). Comments on the motivational status of self-esteem in social identity and intergroup discrimination. European Journal of Social Psychology, 18, 317-334. doi:10.1002/ejsp.2420180403

Albert, S., \& Whetten, D. A. (1985). Organizational identity. In L. L. Cummings \& B. M. Staw (Eds.), Research in organizational behaviour (Vol. 7, pp. 263-295). Greenwich: JAI Press.

Allport, G. (1954). The nature of prejudice. Reading, MA: Addison-Wesley.

Ancona, D. G., Goodman, P. S., Lawrence, B. S., \& Tushman, M. L. (2001). Time: A new research lens. Academy of Management Review, 26, 645-663. doi:10.5465/AMR.2001.5393903 
Arrow, H., Poole, M. S., Henry, K. B., Wheelan, S., \& Moreland, R. (2004). Time, change, and development: The temporal perspective on groups. Small Group Research, 35, 73-105. doi:10.1177/1046496403259757

Barnes, C. M., Hollenbeck, J. R., Wagner, D. T., DeRue, D. S., Nahrgang, J. D., \& Schwind, K. M. (2008). Harmful help: The costs of backing-up behavior in teams. Journal of Applied Psychology, 93, 529-539. doi:10.1037/0021-9010.93.3.529

Baron, R. M., \& Kenny, D. A. (1986). The moderator - Mediator variable distinction in social psychological research: Conceptual, strategic, and statistical considerations. Journal of Personality and Social Psychology, 51, 1173-1182. doi:10.1037/0022-3514.51.6.1173

Binder, J., Brown, R., Zagefka, H., Funke, F., Kessler, T., Mummendey, A., . . \& Leyens, J. P. (2009). Does contact reduce prejudice or does prejudice reduce contact? A longitudinal test of the contact hypothesis among majority and minority groups in three European countries. Journal of Personality \& Social Psychology, 96, 843-856. doi:10.1037/a0013470

Bliese, P. D. (2000). Within-group agreement, non-independence, and reliability: Implications for data aggregation and analysis. In K. J. Klein \& S. W. J. Kozlowski (Eds.), Multilevel theory, research, and methods in organizations: Foundations, extensions, and new directions (pp. 349-381). San Francisco, CA: Jossey-Bass.

Bliese, P. D., \& Ployhart, R. E. (2002). Growth modeling using random coefficient models: Model building, testing, and illustrations. Organizational Research Methods, 5, 362-387. doi: $10.1177 / 109442802237116$

Brewer, M. B. (1991). The social self: On being the same and different at the same time. Personality and Social Psychology Bulletin, 17, 475-482. doi:10.1177/0146167291175001

Brown, M. E., \& Treviño, L. K. (2006). Charismatic leadership and workplace deviance. Journal of Applied Psychology, 91, 954-962. doi:10.1037/0021-9010.91.4.954

Caldwell, B. (2005). Multi-team dynamics and distributed expertise in mission operations. Aviation, Space, and Environmental Medicine, 76(6, Suppl.), B145-B153.

Carnevale, P. J., \& Probst, T. M. (1998). Social values and social conflict in creative problem solving and categorization. Journal of Personality and Social Psychology, 74, 1300-1309. doi:10.1037/0022-3514.74.5.1300

Chan, D. (1998). Functional relations among constructs in the same content domain at different levels of analysis: A typology of composition models. Journal of Applied Psychology, 83, 234246. doi:10.1037/0021-9010.83.2.234

Chen, G., \& Bliese, P. D. (2002). The role of different levels of leadership in predicting self-and collective efficacy: Evidence for discontinuity. Journal of Applied Psychology, 87, 549-556. doi:10.1037/0021-9010.87.3.549

Chen, G., Kanfer, R., DeShon, R. P., Mathieu, J. E., \& Kozlowski, S. W. J. (2009). The motivating potential of teams: Test and extension of cross-level model of motivation in teams. Organizational Behavior and Human Decision Processes, 110(1), 45-55. doi:10.1016/ j.obhdp.2009.06.006

Chen, G., \& Mathieu, J. E. (2008). Goal orientation dispositions and performance trajectories: The roles of supplementary and complementary situational inducements. Organizational Behavior and Human Decision Processes, 106, 21-38. doi:10.1016/j.obhdp.2007.11.001

Conger, J. A., \& Kanungo, R. A. (1987). Towards a behavioral theory of charismatic leadership in organizational settings. Academy of Management Review, 12, 637-647. doi:10.5465/ AMR.1987.4306715

Cronin, M. A., \& Weingart, L. R. (2007). Representational gaps, information processing, and conflict in functionally diverse teams. Academy of Management Review, 32, 761-773. doi:10.5465/AMR.2007.25275511

Culpepper, S. A., \& Aguinis, H. (2011). R is for revolution: A cutting-edge, free, open source statistical Package. Organizational Research Methods, 14, 735-740. doi:10.1177/1094428 109355485 
Davison, R. B., Hollenbeck, J. R., Barnes, C. M., Sleesman, D. J., \& Ilgen, D. R. (2012). Coordinated action in multiteam systems. Journal of Applied Psychology, 97, 808-824. doi:10.1037/ a0026682

De Dreu, C. K. W. (2008). The virtue and vice of workplace conflict: Food for (pessimistic) thought. Journal of Organizational Behavior, 29, 5-18. doi:10.1002/job.474

De Dreu, C. K. W., \& Weingart, L. R. (2003). Task and relationship conflict, team performance, and team member satisfaction: A meta-analysis. Journal of Applied Psychology, 88, 741-749. doi:10.1037/0021-9010.88.4.741

De Wit, F. R. C., Greer, L. L., \& Jehn, K. A. (2012). The paradox of intragroup conflict: A meta-analysis. Journal of Applied Psychology, 97, 360-390. doi:10.1037/a0024844

DeChurch, L. A., Burke, C. S., Shuffler, M. L., Lyons, R., Doty, D., \& Salas, E. (2011). A historiometric analysis of leadership in mission critical multiteam environments. The Leadership Quarterly, 22, 152-169. doi:10.1016/j.leaqua.2010.12.013

DeChurch, L. A., \& Marks, M. A. (2006). Leadership in multiteam systems. Journal of Applied Psychology, 91, 311-329. doi:10.1037/0021-9010.91.2.311

DeChurch, L. A., \& Zaccaro, S. J. (2010). Perspectives: Teams Won't Solve This Problem. Human Factors: The Journal of the Human Factors and Ergonomics Society, 52, 329-334. doi:10.1177/0018720810374736

Doosje, B., Ellemers, N., \& Spears, R. (1995). Perceived intragroup variability as a function of group status and identification. Journal of Experimental Social Psychology, 31, 410-436. doi:10.1006/jesp.1995.1018

Dukerich, J. M., Golden, B. R., \& Shortell, S. M. (2002). Beauty is in the eye of the beholder: The impact of organizational identification, identity, and image on the cooperative behaviors of physicians. Administrative Science Quarterly, 47, 507-533. doi:10.2307/ 3094849

Dutton, J. E., Dukerich, J. M., \& Harquail, C. V. (1994). Organizational images and member identification. Administrative Science Quarterly, 39, 239-263. doi:10.2307/2393235

Eisenbeiss, K. K., \& Otten, S. (2008). When do employees identify? An analysis of cross sectional and longitudinal predictors of training group and organizational identification. Journal of Applied Social Psychology, 38, 2132-2151. doi:10.1111/j.1559-1816.2008.00384.x

Field, A., Miles, J., \& Field, Z. (2012). Discovering Statistics using R. London, UK: Sage.

Fiol, C. M., Pratt, M. G., \& O'Connor, E. J. (2009). Managing intractable identity conflicts. Academy of Management Review, 34(1), 32-55. doi:10.5465/AMR.2009.35713276

Firth, B., Hollenbeck, J., Miles, J., Ilgen, D., \& Barnes, C. (2015). Same page, different books: Extending representational gaps theory to enhance performance in multiteam systems. Academy of Management Journal, 58, 813-835. doi:10.5465/amj.2013.0216

Gaertner, S. L., Dovidio, J. F., Anastasio, P. A., Bachman, B. A., \& Rust, M. C. (1993). The common ingroup identity model: Recategorisation and the reduction of inter-group bias. European Review of Social Psychology, 4, 3-24. doi:10.1080/14792 779343000004

Gaertner, S. L., Dovidio, J. F., \& Bachman, B. A. (1996). Revisiting the contact hypothesis: The induction of a common ingroup identity. International Journal of Intercultural Relations, 20, 271-290. doi:10.1016/0147-1767(96)00019-3

Gaertner, S. L., Dovidio, J. F., Rust, M. C., Nier, J. A., Banker, B. S., Ward, C. M., et al. (1999). Reducing intergroup bias: Elements of intergroup cooperation. Journal of Personality and Social Psychology, 76, 388-402. doi:10.1037/0022-3514.76.3.388

George, J. M., \& Jones, G. R. (2000). The role of time in theory and theory building. Journal of Management, 26, 657-684. doi:10.1177/014920630002600404

Giessner, S. R., \& Mummendey, A. (2008). United we run, divided we fail? Effects of cognitive merger representations and performance feedback on merging groups. European Journal of Social Psychology, 38, 412-435. doi:10.1002/ejsp.439

Glick, W. H. (1985). Conceptualizing and measuring organizational and psychological climate: Pitfalls in multilevel research. Academy of Management Review, 10(3), 601-616. doi:10.5465/ AMR.1985.4279045 
Glynn, M. A., Kazanjian, R., \& Drazin, R. (2010). Fostering innovation in complex product development settings: The role of team member identity and interteam Interdependence. Journal of Product Innovation Management, 27, 1082-1095. doi:10.1111/j.1540-5885. 2010.00772.x

Gonzalez, R., \& Brown, R. J. (2003). Generalization of positive attitude as a function of subgroup and superordinate group identifications in intergroup contact. European Journal of Social Psychology, 33, 195-214. doi:10.1002/ejsp.140

Goodwin, G. F., Essens, P. J. M. D., \& Smith, D. (2012). Multiteam systems in the public sector. In S. J. Zaccaro, M. A. Marks \& L. A. DeChurch (Eds.), Multiteam systems: An organizational form for dynamic and complex environments (pp. 53-78). New York, NY: Taylor \& Francis.

Hackman, J. R., \& Wageman, R. (2005). A theory of team coaching. Academy of Management Review, 30, 269-287. doi:10.5465/AMR.2005.16387885

Hinsz, V. B., \& Betts, K. R. (2012). Conflict in multiteam situations. In S. J. Zaccaro, M. A. Marks \& L. A. DeChurch (Eds.), Multiteam systems: An organizational form for dynamic and complex environments (pp. 395-427). New York, NY: Taylor \& Francis.

Hoegl, M., \& Weinkauf, K. (2005). Managing task interdependencies in multi-team projects: A longitudinal study. Journal of Management Studies, 42, 1287-1308. doi:10.1111/j.14676486.2005.00542.x

Hoegl, M., Weinkauf, K., \& Gemuenden, H. G. (2004). Interteam coordination, project commitment, and teamwork in multiteam R\&D projects: A longitudinal study. Organization Science, 15(1), 38-55. doi:10.1287/orsc. 1030.0053

Hogg, M. A., \& Terry, D. J. (2000). Social identity and self-categorization processes in organizational contexts. Academy of Management Review, 25(1), 121-140. doi:10.5465/AMR.2000.2791606

Hogg, M. A., Terry, D. J., \& White, K. M. (1995). A tale of two theories: A critical comparison of identity theory with social identity theory. Social Psychology Quarterly, 58(4), 255-269. doi: $10.2307 / 2787127$

Hogg, M. A., van Knippenberg, D., \& Rast, III, D. E. (2012). Intergroup leadership in organizations: Leading across group and organizational boundaries. Academy of Management Review, 37(2), 232-255. doi:10.5465/amr.2010.0221

Hornsey, M. J., \& Hogg, M. A. (2000). Assimilation and diversity: An integrative model of subgroup relations. Personality \& Social Psychology Review, 4(2), 143-156. doi:10.1207/S15327957 PSPR0402_03

Hox, J. J. (2010). Multilevel analysis: Techniques and applications. New York, NY: Taylor \& Francis.

Hu, L., \& Bentler, P. M. (1999). Cutoff criteria for fit indexes in covariance structure analysis: Conventional criteria versus new alternatives. Structural Equation Modeling, 6, 1-55. doi:10.1080/10705519909540118

Jackson, J. W. (2002). Intergroup attitudes as a function of different dimensions of group identification and perceived intergroup conflict. Self and Identity, 1(1), 11-33. doi:10.1080/ 152988602317232777

Jehn, K. A. (1995). A multimethod examination of the benefits and detriments of intragroup conflict. Administrative Science Quarterly, 40, 256-282. doi:10.2307/2393638

Jehn, K. A., Chadwick, C., \& Thatcher, S. M. B. (1997). To agree or not to agree: The effects of value congruence, individual demographic dissimilarity, and conflict on workgroup outcomes. International Journal of Conflict Management, 8, 287-305. doi:10.1108/eb022799

Jehn, K. A., \& Mannix, E. A. (2001). The dynamic nature of conflict: A longitudinal study of intragroup conflict and group performance. Academy of Management Journal, 44, 238-251. doi: $10.2307 / 3069453$

Kanfer, R., \& Ackerman, P. L. (1989). Motivation and cognitive abilities: An integrative/ aptitude-treatment interaction approach to skill acquisition. Journal of Applied Psychology, 74, 657-690. doi:10.1037/0021-9010.74.4.657

Kenny, D. A., Kaniskan, B., \& McCoach, D. B. (2013). The performance of RMSEA in models with small degrees of freedom. Unpublished paper. University of Connecticut. 
Kenny, D. A., Korchmaros, J. D., \& Bolger, N. (2003). Lower level mediation in multilevel models. Psychological Methods, 8(2), 115-128. doi:10.1037/1082989X.8.2.115

Klein, K. J., Conn, B., Smith, D. B., \& Sorra, J. S. (2001). Is everyone in agreement? An exploration of within-group agreement in employee perceptions of the work environment. Journal of Applied Psychology, 86, 3-16. doi:10.1037/0021-9010.86.1.3

Kramer, R. M., \& Brewer, M. B. (1984). Effects of group identity on resource use in a simulated commons dilemma. Journal of Personality and Social Psychology, 46, 1044-1057. doi:10.1037/0022-3514.46.5.1044

LeBreton, J. M., \& Senter, J. L. (2008). Answers to twenty questions about interrater reliability and interrater agreement. Organizational Research Methods, 11, 815-852. doi:10.1177/ 1094428106296642

Li, J., \& Hambrick, D. C. (2005). Factional groups: A new vantage on demographic faultlines, conflict, and disintegration in work teams. Academy of Management Journal, 48, 794-813. doi:10.5465/AMJ.2005.18803923

Marks, M. A. (2000). A critical analysis of computer simulations for conducting team research. Small Group Research, 31, 653-675. doi:10.1177/104649640003100602

Marks, M. A., DeChurch, L. A., Mathieu, J. E., Panzer, F. J., \& Alonso, A. (2005). Teamwork in multiteam systems. Journal of Applied Psychology, 90, 964-971. doi:10.1037/00219010.90.5.964

Marks, M. A., \& Luvison, D. (2012). Product launch and strategic alliance MTSs. In S. J. Zaccaro, M. A. Marks \& L. A. DeChurch (Eds.), Multiteam systems: An organization form for dynamic and complex environments (pp. 365-394). New York, NY: Taylor \& Francis.

Marks, M. A., Mathieu, J. E., \& Zaccaro, S. J. (2001). A temporally based framework and taxonomy of team processes. Academy of Management Review, 26, 356-376. doi:10.5465/AMR. 2001.484578

Mathieu, J., Marks, M. A., \& Zaccaro, S. J. (2001). Multi-team systems. In N. Anderson, D. Ones, H. K. Sinangil \& C. Viswesvaran (Eds.), International handbook of work and organizational psychology (Vol. 2, pp. 289-313). London, UK: Sage.

Meth, N. D., Lawless, B., \& Hawryluck, L. (2009). Conflicts in the ICU: Perspectives of administrators and clinicians. Intensive Care Medicine, 35, 2068-2077. doi:10.1007/s00134-009-1639-5

Moore, D. A., Kurtzberg, T. R., Thompson, L. L., \& Morris, M. W. (1999). Long and short routes to success in electronically mediated negotiations: Group affiliations and good vibrations. Organizational Behavior \& Human Decision Processes, 77, 22-43. doi:10.1006/ obhd.1998.2814

Mortensen, M., \& Hinds, P. J. (2001). Conflict and shared identity in geographically distributed teams. International Journal of Conflict Management, 12, 212-238. doi:10.1108/ eb022856

Murase, T., Carter, D. R., DeChurch, L. A., \& Marks, M. A. (2014). Mind the gap: The role of leadership in multiteam system collective cognition. The Leadership Quarterly, 25(5), 972-998. doi:10.1016/j.leaqua.2014.06.003

O'Leary, M. B., Mortensen, M., \& Woolley, W. (2011). Multiple team membership: A theoretical model of its effects on productivity and learning for individuals and teams. Academy of Management Review, 36(3), 461-478. doi:10.5465/AMR.2011.61031807

O'Leary, M. B., Woolley, W., \& Mortensen, M. (2012). Multiteam membership in relation to multiteam systems. In S. J. Zaccaro, M. A. Marks \& L. A. DeChurch (Eds.), Multiteam systems: An organizational form for dynamic and complex environments (pp. 141-172). New York, NY: Taylor \& Francis.

Omodei, M. M., Taranto, P., \& Wearing, J. (2003). Networked Fire Chief (Version 1. 33) [Computer program]. Melbourne, Vic., Australia: La Trobe University.

Peterson, R. S., \& Behfar, K. J. (2003). The dynamic relationship between performance feedback, trust, and conflict in groups: A longitudinal study. Organizational Behavior and Human Decision Processes, 92, 102-112. doi:10.1016/S0749-597 8(03) 00090-6 
Porter, C. O. L. H., Gogus, C. I., \& Yu, R. C.-F. (2010). When does teamwork translate into improved team performance? A resource allocation perspective. Small Group Research, 41, 221-248. doi:10.1177/1046496409356319

Pratt, M. G., Rockmann, K. W., \& Kaufmann, J. B. (2006). Constructing professional identity: The role of work and identity learning cycles in the customization of identity among medical residents. Academy of Management Journal, 49, 235-262. doi:10.5465/AMJ.2006.20786060

Preacher, K. J., \& Selig, J. P. (2012). Advantages of Monte Carlo confidence intervals for indirect effects. Communication Methods and Measures, 6, 77-98. doi:10.1080/ 19312458.2012.679848

Richter, W., West, M. A., van Dick, R., \& Dawson, J. F. (2006). Boundary spanners' identification, intergroup contact, and effective intergroup relations. Academy of Management Journal, 49, 1252-1269. doi:10.5465/AMJ.2006.23478720

Riketta, M., \& van Dick, R. (2005). Foci of attachment in organizations: A meta-analytic comparison of the strength and correlates of workgroup versus organizational identification and commitment. Journal of Vocational Behavior, 67, 490-510. doi:10.1016/j.jvb.2004. 06.001

Roe, R. A., Gockel, C., \& Meyer, B. (2012). Time and change in teams: Where we are and where we are moving. European Journal of Work Organizational Psychology, 21, 629-656. doi:10.1080/1359432X.2012.729821

Selig, J. P., \& Preacher, K. J. (2008). Monte Carlo method for assessing mediation: An interactive tool for creating confidence intervals for indirect effects [Computer software]. Retrieved from http://quantpsy.org/

Simons, T. L., \& Peterson, R. S. (2000). Task conflict and relationship conflict in top management teams: The pivotal role of intragroup trust. Journal of Applied Psychology, 85(1), 102-111. doi:10.1037/0021-9010.85.1.102

Singer, J. D., \& Willett, J. B. (2003). Applied longitudinal data analysis: Modeling change and event occurrence. New York, NY: Oxford University Press. doi:10.1093/acprof:oso/9780195152968. 001.0001

Srivastava, A., Bartol, K. M., \& Locke, E. A. (2006). Empowering leadership in management teams: Effects on knowledge sharing, efficacy, and performance. Academy of Management Journal, 49, 1239-1251. doi:10.5465/AMJ.2006.23478718

Standifer, R. L. (2012). The emergence of temporal coordination within multiteam systems. In S. J. Zaccaro, M. A. Marks \& L. A. DeChurch (Eds.), Multiteam systems: An organizational form for dynamic and complex environments (pp. 395-427). New York, NY: Taylor \& Francis.

Tajfel, H. (1982). Instrumentality, identity and social comparisons. In H. Tajfel (Ed.), Social identity and intergroup relations (pp. 483-507). Cambridge, UK: Cambridge University Press.

Tajfel, H., Billig, M. G., Bundy, R. F., \& Flament, C. (1971). Social categorization and intergroup behaviour. European Journal of Social Psychology, 1, 149-177. doi:10.1002/ejsp.24200 10202

Tjosvold, D. (1998). Cooperative and competitive goal approach to conflict: Accomplishments and challenges. Applied Psychology, 47, 285-313. doi:10.1111/j.1464-0597.1998.tb00025.x

Uitdewilligen, S., \& Waller, M. J. (2012). Adaptation in multiteam systems: The role of temporal semistructures. In S. J. Zaccaro, M. A. Marks \& L. A. DeChurch (Eds.), Multiteam systems: An organizational form for dynamic and complex environments (pp. 365-394). New York, NY: Taylor \& Francis.

Ullrich, J., Wieseke, J., Christ, O., Schulze, M., \& Van Dick, R. (2007). The Identity Matching Principle: Corporate and organizational identification in a franchising system. British Journal of Management, 18, 29-44. doi:10.1111/j.1467-8551.2007.00524.x

van der Vegt, G. S., \& Bunderson, J. S. (2005). Learning and performance in multidisciplinary teams: The importance of collective team identification. Academy of Management Journal, 48, 532 547. doi:10.5465/AMJ.2005.17407918 
van Dick, R., van Knippenberg, D., Kerschreiter, R., Hertel, G., \& Wieseke, J. (2008). Interactive effects of work group and organizational identification on job satisfaction and extra-role behavior. Journal of Vocational Behavior, 72, 388-399. doi:10.1016/j.jvb.2007.11.009

van Knippenberg, D., \& van Schie, E. C. M. (2000). Foci and correlates of organizational identification. Journal of Occupational and Organizational Psychology, 73, 137-147. doi:10.1348/096317900166949

Vora, D., \& Kostova, T. (2007). A model of dual organizational identification in the context of the multinational enterprise. Journal of Organizational Behavior, 28, 327-350. doi:10.1002/ job. 422

Vora, D., Kostova, T., \& Roth, K. (2007). Roles of subsidiary managers in multinational corporations: The effect of dual organizational identification. Management International Review, 47, 595620. doi:10.1007/s11575-007-0031-3

Wilson, K. A., Bedwell, W. L., Lazzara, E. H., Salas, E., Burke, C. S., Estock, J. L., . . Conkey, C. (2009). Relationships between game attributes and learning outcomes: Review and research proposals. Simulation \& Gaming, 40, 217-266. doi:10.1177/1046878108321866

Received 22 November 2013; revised version received 23 February 2015 